JOURNAL

of Health Inequalities

\title{
Global public health - challenges and leadership
}

\author{
Peter Boyle \\ International Prevention Research Institute, Lyon, France \\ Strathclyde Institute of Global Public Health, Lyon, France
}

\begin{abstract}
Although death cannot be prevented or escaped, many deaths have avoidable causes. The articles presents an overview of global public health and explores major causes of premature deaths worldwide: chronic diseases and unequal access to medical care, tobacco, alcohol, lack of adequate food, malnutrition, obesity, lack of sanitation and clean water, smog, trauma, and unexploded munitions. The analysis leads to a conclusion that coordinated global effort if necessary to improve the health of the population and stimulate the impact of a variety of factors on health.
\end{abstract}

KEY WORDS: global public health, premature death, causes of death.

ADDRESS FOR CORRESPONDENCE: Peter Boyle, International Prevention Research Institute, 15 chemin du Saquin, 69130 Ecully ouest Lyon, France, e-mail: peter.boyle@i-pri.org

\section{INTRODUCTION}

The Constitution of the World Health Organization (WHO) defines health as a "state of complete physical, mental and social well-being and not merely the absence of disease or infirmity". The Constitution was adopted by the International Health Conference held in New York in 1946, signed by the representatives of 61 States and entered into force on $7^{\text {th }}$ April 1948. While this Constitution has been amended subsequently, this definition has remained unchanged [1]. Health is a resource for everyday life, not the objective of living. Health is a positive concept emphasizing social and personal resources, as well as physical capacities.

Death ultimately cannot be prevented. Each year there are approximately 20 million deaths worldwide in each of the age groups 0-34, 35-69 and 70 and older. Priorities include the avoidance of deaths which may be preventable and the avoidance of deaths in children and in middle age (35-69). In the context of global public health, these goals are not being achieved. Each year there are approximately 10 million deaths in children under the age of five from a variety of preventable causes including neonatal deaths, respiratory conditions, diarrhoea, malaria, measles, HIV/AIDS and injury. Most of these deaths are among populations in lower-resource settings and undernutrition is an underlying contributory factor in over one-third of these deaths.
In addition, two thirds of all deaths globally occur before the age of 69 . As with child mortality, many of these deaths occur in low-resource regions of the world. The greatest disparity is between higher-resource and lower-resource regions. However, these differences exist not only between the resource-rich western countries and the resource-deprived regions of Africa and Asia, but are also present, although to a lesser extent, within individual continents, including Europe (Fig. 1) [2]. The differences in the percentage of deaths before the age of 65 in the European Union (EU) in 2014 between the established EU Member States (EU15) and the more recent Member States from Central and Eastern Europe (EU10) are quite remarkable. In men, in the EU15 20.5\% of deaths occurred in middle-age compared with $30.2 \%$ in EU10. In women, the corresponding figures were $10.9 \%$ in EU15 and $15.8 \%$ in EU10.

\section{FUTURE EVOLUTION OF THE GLOBAL SITUATION}

The world population is currently 7.5 billion and is estimated to grow to 8.5 billion by 2030 . The population will also age significantly. The growth and ageing of populations will bring increases in many common chronic diseases, including cancer, cardiovascular disease, diabetes and chronic obstructive pulmonary disease (COPD). Population growth until 2100 will be driven by the 
Women

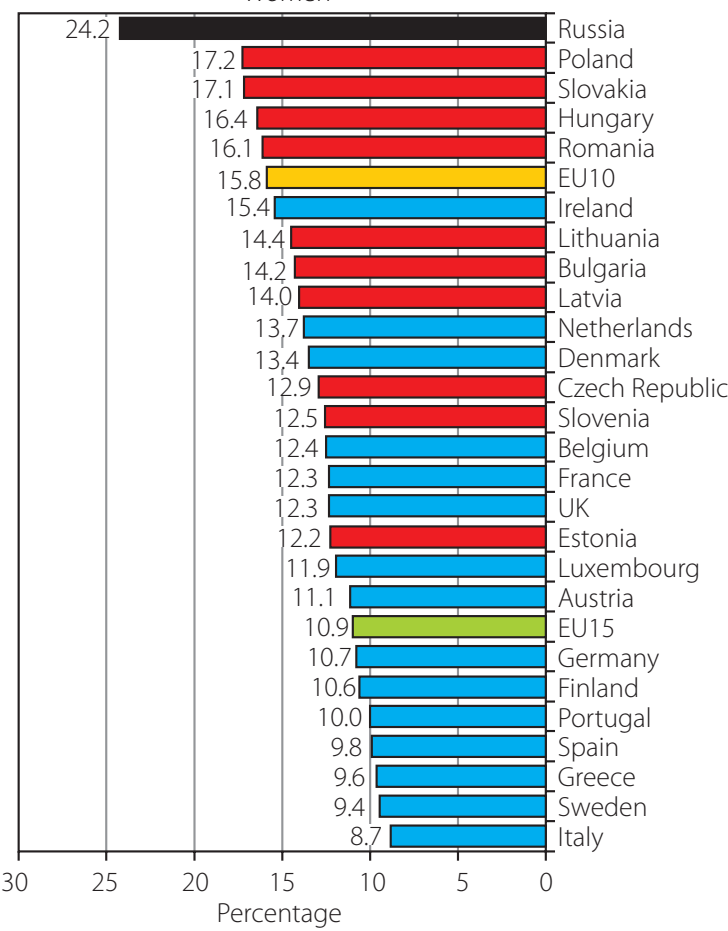

Men

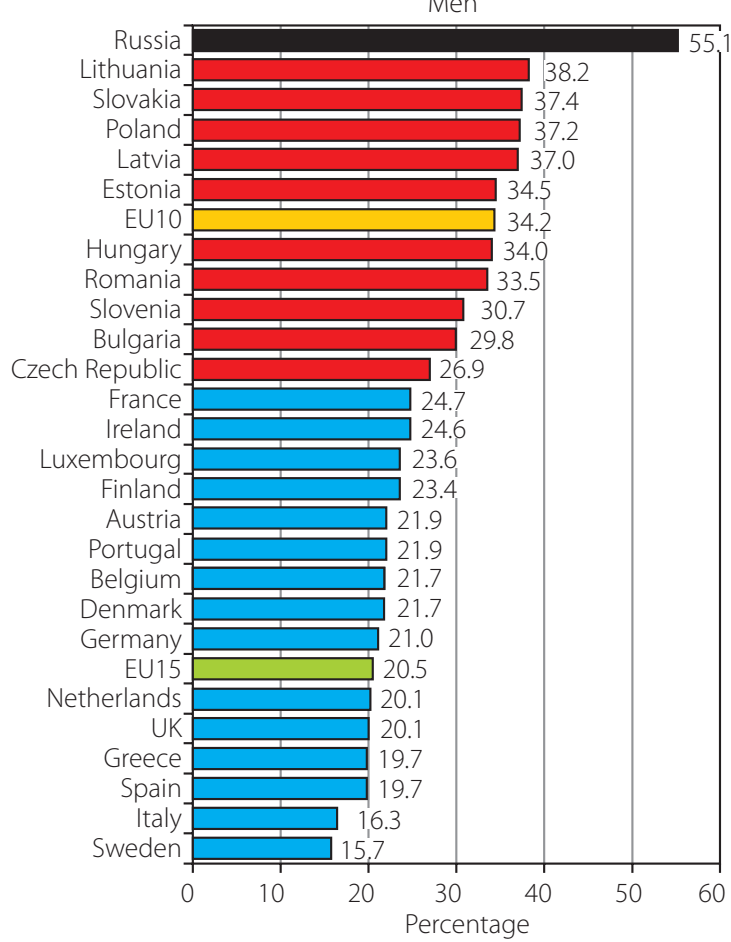

FIG. 1. Percentage of deaths in European Countries in 2014 which occur in men and women under the age of 65 [2]

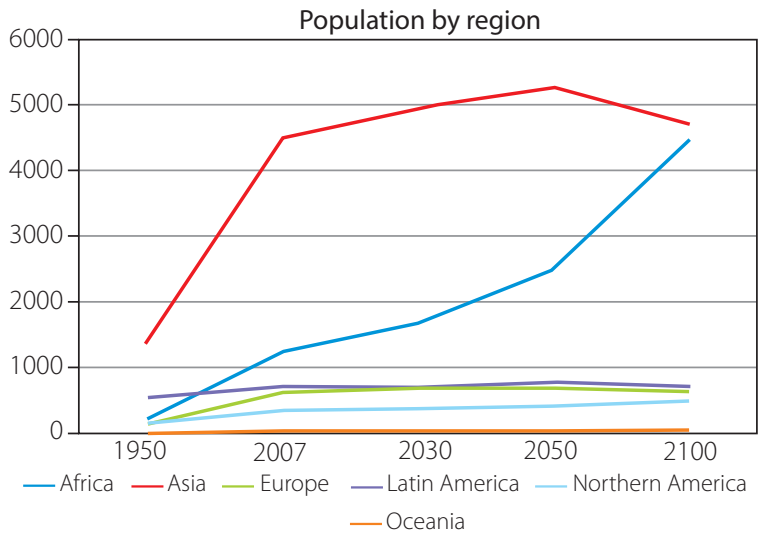

FIG. 2. Evolution of global population by region. Estimated total population in 1,000s [3]

growth of the population of Africa, which will rival that of Asia by the end of this century (Fig. 2) [3]. The population of the higher-resource regions will remain fairly constant throughout this century.

Currently, it is estimated that there will be 18.6 million new cases of cancer diagnosed this year [4] and this has been estimated to reach 28 million by 2030 , taking the increased and ageing population into account [5]. There are an estimated 425 million people worldwide aged 20-79 with diabetes and this is estimated to grow to a total of 629 million by 2045 [6]. The situation is dramatic: taking the estimated 352 million persons with impaired glucose tolerance (IGT) into account, then there are over three quarter of a billion persons with diabetes or pre-diabetes currently. It is conceivable that by 2045 there will be more than one billion people with these conditions.

In high-resource countries, the mortality rates for cancer (all forms combined), cardiovascular disease and myocardial infarction have been decreasing. This is due to a number of factors, but key among them is the development of innovative treatments (e.g. for testicular cancer, Hodgkin's lymphoma, colorectal cancer) and innovative prevention (e.g. use of anti-hypertensives, statins and smoking cessation in prevention of cardiovascular disease, and smoking cessation in prevention of lung cancer and several other forms of cancer). There are good reasons to believe that these major declines will continue for the foreseeable future.

In complete contrast to this positive situation in highresource countries, the situation in low-resource countries is of great concern [7]. There are 55 countries in the world which do not have a single radiotherapy machine, 30 of which are in Africa. There are 29 countries in Africa where importation of opioid drugs for palliative care is forbidden. Of the nearly 600 drugs on the 2015 WHO list of essential medicines, 44 are used to treat cancer (38 chemotherapeutics and six hormones). Among the 37 countries in the African Region subscribing to the WHO Essential Medicines List, the median number of chemotherapeutics adapted for national formularies is 15 [8].

Given the rapid growth and ageing of the African population, the existing disparity between high-resource 
countries and lower-resource regions such as Africa can only widen unless immediate and effective action is taken.

\section{OVERVIEW OF GLOBAL PUBLIC HEALTH}

Out of the 7.5 billion people living on the planet, over 1 billion people do not have access to clean drinking water and 2 billion do not have access to sanitation. One billion people are hungry and nearly one billion are under-nourished. One third of city dwellers live in a slum. In the race to find ways to feed and supply clean water and sanitation to the rapidly growing population, climate change will present a major challenge.

It is estimated that air pollution causes 9 million deaths each year [9]. Tobacco smoking causes 7 million deaths; AIDS, tuberculosis and malaria cause 3 million deaths; child and mother malnutrition causes half a million deaths; road traffic accidents cause a further half million deaths; and war and murder contribute to 300,000 deaths [10].

Tobacco smoking caused an estimated 100 million deaths last century and, based on current smoking levels, it will likely cause 1 billion deaths this century. Globally, alcohol drinking was the seventh leading risk factor for deaths in 2016, accounting for $2.2 \%$ of deaths in women and $6.8 \%$ deaths in men. Among the population aged 15-49 years, alcohol drinking caused 3.8\% of deaths in women and $12.2 \%$ of deaths in men [tuberculosis (1.4\% of total deaths), road injuries (1.2\%), and self-harm (1.1\%)]. For populations aged 50 years and older, cancers accounted for a large proportion of total

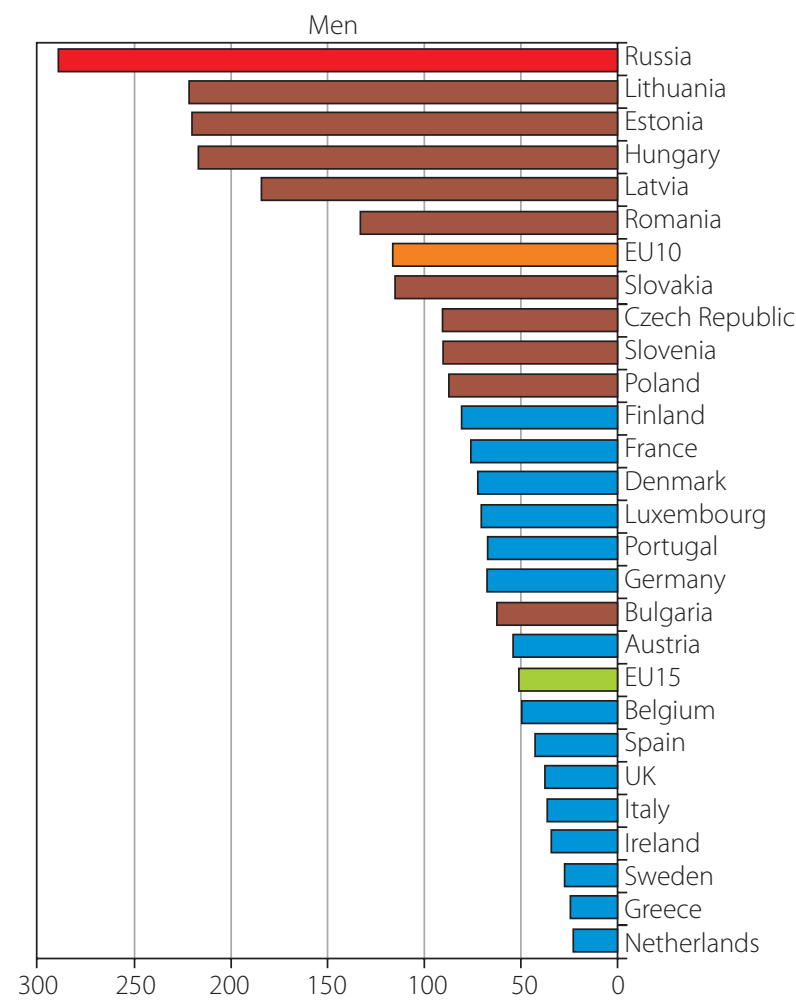

alcohol-attributable deaths in 2016, constituting 27.1\% of total alcohol-attributable deaths in women and $18.9 \%$ of deaths in men. The level of alcohol consumption that minimised harm across health outcomes was zero standard drinks per week [11]. This zero-level is unattainable but there is a clear need to reduce consumption overall, but especially in countries where there are currently high levels of consumption.

The highest alcohol-attributable deaths rates in men and women in Europe are in countries of Central and Eastern Europe (Fig. 3) [12]. While progress has been made against smoking, little action or effect is witnessed regarding alcohol consumption. For example, in Poland there has been a dramatic reduction in cigarette consumption since 1995 (Fig. 4) [13]. This Zatonski effect owes much to the single-handed dedication of Professor Witold A. Zatonski to reducing the harmful health effects of cigarette smoking on the Polish population. In contrast, the lack of decline in alcohol consumption is striking (Fig. 4) [13] and alcohol-attributable mortality is set to continue to increase.

\section{FOOD AND MALNUTRITION}

The problems facing Public Health are global in nature. Unhealthy diets are one of the leading causes of malnutrition worldwide. There are 1.9 billion adults who are overweight or obese and 462 million who are underweight [14] 2 billion people suffer from some form of micronutrient deficiency. 52 million children under five years of age are

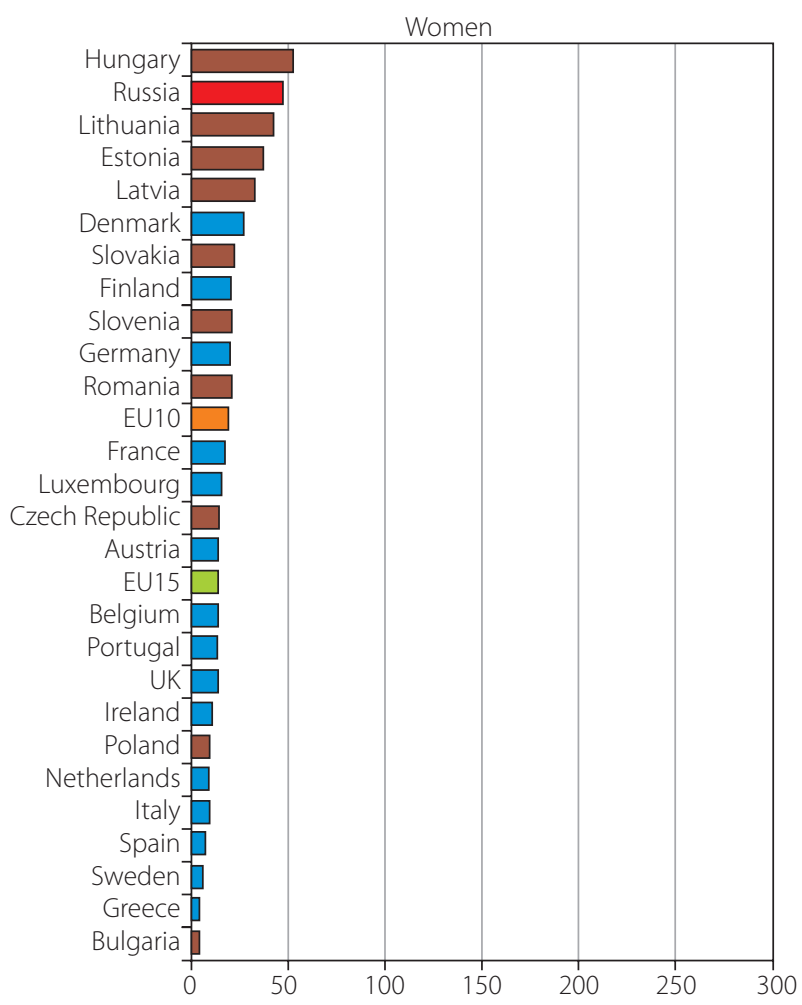

FIG. 3. Alcohol attributable deaths in men and women in Europe [12] 
Cigarettes

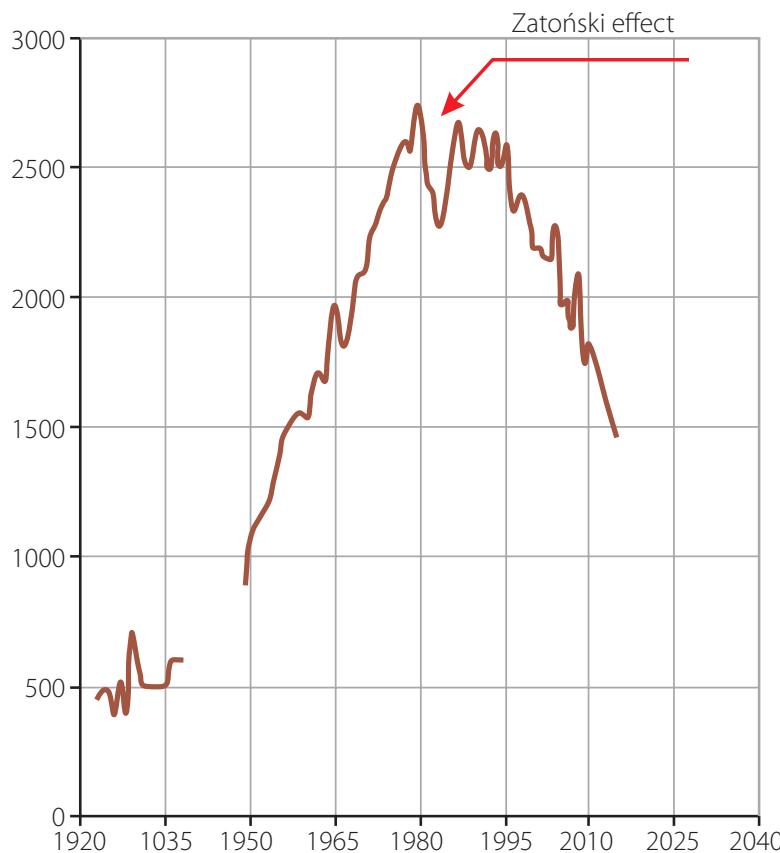

Alcohol

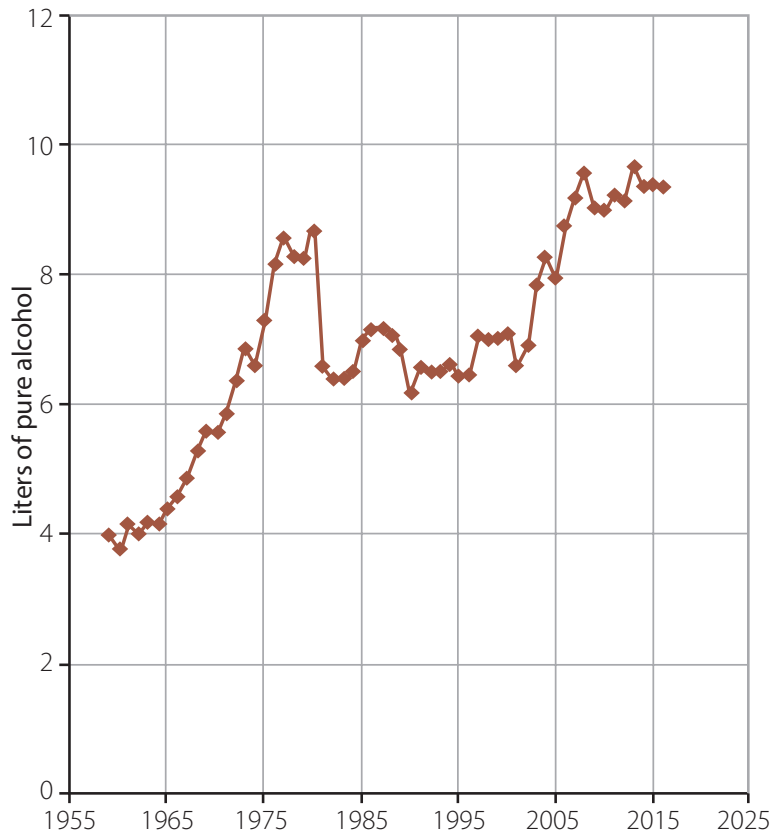

FIG. 4. Trends in per capita cigarette smoking (since 1935) and alcohol consumption (since 1955) in Poland [13]

wasted, and 17 million are severely wasted, 155 million are stunted and 41 million are overweight or obese. Around $45 \%$ of deaths among children under 5 years of age are linked to undernutrition: these mostly occur in low- and middle-income countries. At the same time, in these same countries, rates of childhood overweight and obesity are rising. 795 million people do not get the food they need to live a healthy life. Famine abounds. Since 2016, a famine has been ongoing in Yemen, which has recently been described by the United Nations as potentially becoming the worst in living memory [15], with the country in 'clear and present danger of mass deaths from starvation'. Over 17 million of Yemen's population are at risk including over 3.3 million children and pregnant or lactating women who are suffering from acute malnutrition. The famine is being compounded by an outbreak of cholera, which is resulting in 5,000 new cases daily.

In the $21^{\text {st }}$ century, with effective networks of international aid and plentiful food supply, famine should be a preventable condition. One complicating factor is the price of food. The Food and Agricultural Organisation (FAO) of the United Nations publishes an Annual Food Price Index. After remaining stable for many years, the index started rising in 2004, more than doubled in 2008-2014 and is currently 50\% higher that it was in 2000 and earlier [16].

\section{WATER SAFETY AND SANITATION}

In the mid-nineteenth century, a series of Acts of Parliament in Great Britain introduced measures which contributed greatly to the health of the population. Sir Edwin Chadwick was a pioneer in public health and pre- pared a report [17] which formed the basis of the Public Health Act which was passed by Parliament in 1848. This Act of Parliament empowered the General Board of Health for England and Wales to ensure local authorities were responsible for the provision of water, sewers, drains, road paving and cleaning in populous areas. The overall aim was to improve the health of the population by reducing insanitary exposures. Around the same time, in 1851, vaccination was made compulsory and further legislation (1871) established the creation of vaccination officers to monitor a registration system.

John Snow (1855) [18] published his theory that cholera was transmitted via oral exposure and demonstrated his theory was indeed correct when he identified the water pump in Broad Street (London) as the source of an outbreak in 1854. Over the next decades, amendments to further Public Health Acts made the provision of clean drinking water compulsory as well as the necessity of having lavatories and the collection and disposal of garbage compulsory.

Unfortunately, there are many countries in sub-Saharan Africa today where more than $10 \%$ of deaths are still due to inadequate water and sanitation. In the recent population census in India, conducted in 2011 [19], estimations were made for households and individuals. The population of India was found to be 1.2 billion and there are 246 million households. Of households $46.9 \%$ have lavatories, $63.2 \%$ have a telephone and $47.2 \%$ have a television. However, of the population $49.8 \%$ defecate in public and $53.2 \%$ have a mobile phone.

Vaccination has made a great contribution to public health. Immunization prevents illness, disability and 
death from vaccine-preventable diseases including cervical cancer, diphtheria, hepatitis $\mathrm{B}$, measles, meningitis, mumps, pertussis (whooping cough), pneumonia, polio, rotavirus diarrhoea, rubella and tetanus. Global vaccination coverage remains at $85 \%$, with no significant changes during the past few years and the uptake of new and underused vaccines is increasing. The World Health Organisation estimates that two million infant deaths are prevented each year by vaccines. However, an additional 1.5 million deaths could be avoided if global immunization coverage improves. An estimated 19.9 million children under the age of one did not receive DTP3 vaccine (diphtheria, tetanus and polio) [20].

Table 1 [21] clearly shows the dramatic reductions in death rates from a variety of vaccine preventable diseases over the last century. What were frequent killers were brought under control by vaccination. One unfortunate development in recent years has been the growth of movements against vaccination in a number of countries and a resultant drop in the vaccination rates. Poland is as well one of this country [22]. One recent consequence has been the return of measles in Europe. According to the World Health Organisation, there has been an increase in the numbers of cases of measles in Europe, rising from 5,273 cases in 2017, to 23,927 cases in 2017, and more than 41,000 people have been infected with measles in the first six months of 2018 [23] Measles can be a fatal condition: in the first six months of 2018, there were 37 deaths due to measles in Europe.

\section{TRAUMA AND POST-CONFLICT PUBLIC HEALTH}

According to the Global Burden of Disease, trauma is now responsible for five million deaths each year. Highincome countries have made great strides in reducing trauma-related mortality figures but low-middle income countries been left behind with high trauma-related fatality rates, primarily in the younger population. Much of the progress high-income countries have made in managing trauma rests on advances developed in their armed forces [24].

War has an immediate impact on the lives of those involved whether it is through fatality of infirmity. However, the unwelcome effects of war frequently linger on after hostilities cease. The problem of land-mines comes immediately to mind and its horrendous impact on civilian populations as an important cause of trauma in the postconflict setting.

The effects can be of a much longer term. The French Département du Déminage recovers about 900 tons of unexploded munitions every year mainly from the Great War of 1914-1918. Since 1945, approximately 630 French clearers have died handling unexploded munitions [25]. Twenty members of Belgian Explosive Ordnance Disposal (DOVO) have died disposing of First World War munitions since the unit was formed in 1919. Civilian deaths are also common. In just the area around Ypres, 260 people have been killed and 535 have been injured by
TABLE 1. Annual deaths rates per million in England and Wales in the period 1948-54 and 1971

\begin{tabular}{|l|c|c|}
\hline Cause of death & $1948-1954$ & 1971 \\
\hline Tuberculosis & 2,901 & 13 \\
\hline Bronchitis, influenza & 2,239 & 603 \\
\hline Scarlet fever, diphtheria & 1,016 & 0 \\
\hline Whooping cough & 423 & 1 \\
\hline Measles & 342 & 0 \\
\hline Smallpox & 263 & 0 \\
\hline Upper respiratory tract infections & 75 & 2 \\
\hline
\end{tabular}

Source: Cairns J, Cancer Science and Society [21].

unexploded munitions since the end of the First World War. Poisonous gas remains viable and will corrode and release their gas content frequently causing severe burns to those who come in contact with such shells.

War is preventable and therefore so are post-conflict problems in public health. The number of Americans killed on battlefields in all wars in history has been estimated as $1,396,763$. Since 1968, the number of Americans killed by firearms in the United States is estimated to be $1,516,863$ [26].

\section{CONCLUDING REMARKS}

Important causes of death in the world include tobacco, alcohol, lack of adequate food, malnutrition, obesity, lack of physical activity, trauma, lack of sanitation, lack of clean water and clean air - smog [27], lack of electricity and major sources of infectious disease. Many deaths have avoidable causes. Poverty and deprivation are the major causes of premature death worldwide. Many successful projects in low-resource countries are a result of charitable work from higher-resource countries. It is impossible to escape the conclusion that governments and international organisations must do more to eradicate the disparities in health which exist. The task should not be left to charitable efforts. There is a striking need for a coordinated global effort.

Many statistics have been employed above describing the health of the population and the impact of a variety of factors on health. It is essential always to remember that "statistics are patients with the tears wiped away".

\section{ACKNOWLEDGEMENTS}

This text is based on the Inauguration Lecture (Global Public Health: Challenges and Leadership) presented during the Ceremonial Inauguration of the Academic Year at The President Stanisław Wojciechowski State University of Applied Sciences in Kalisz (Poland) on $15^{\text {th }}$ October, 2018. During the Ceremony Professor Boyle was conferred with the Honorary title Meritorious for the President Stanisław Wojciechowski State University of Applied Sciences, Kalisz, Poland. 


\section{DISCLOSURE}

The author reports no conflict of interests.

\section{References}

1. World Health Organization. Basic documents. Forty-eighth edition. WHO, Geneva 2014. Available from: http://apps.who. $\mathrm{int} / \mathrm{gb} / \mathrm{bd} / \mathrm{PDF} / \mathrm{bd} 48 / \mathrm{basic}$-documents-48th-edition-en. pdf\#page=1 (accessed: 19 October 2018).

2. Janik-Koncewicz K, Herbeć A, Zatoński M, et al. Building health literacy in a Polish region: protocol for the POWER project in Lower Silesia. J Health Inequal 2018; 4: 27-30.

3. United Nations, Department of Economic and Social Affairs, Population Division. World Population Prospects: The 2017 Revision, Key Findings and Advance Tables. Working Paper No. ESA/P/WP/248. United Nations, 2017.

4. Cancer tomorrow. Available from: http://gco.iarc.fr/tomorrow/ home (accessed: 19 October 2018).

5. Boyle P, Levin B (eds.). World Cancer Report 2008. IARC, Lyon 2008.

6. International Diabetes Federation. IDF Diabetes Atlas Eighth Edition. IDF, 2017.

7. Boyle P, Ngoma T, Sullivan R, et al. (eds.). The State of Oncology in Africa, 2015. iPRI Scientific Publication 4. iPRI, Lyon 2016

8. Brawley OW. Medical Oncology in Africa. In: The State of Oncology in Africa 2015: iPRI Scientific Publication 4. Boyle P, Ngoma T, Sullivan R, et al. (eds). iPRI, Lyon 2016.

9. Burnett R, Chena H, Szyszkowicza M, et al. Global estimates of mortality associated with longterm exposure to outdoor fine particulate matter. Proc Natl Acad Sci U S A 2018; 115: 9592-9597.

10. Landrigan PJ, Fuller R, Acosta NJR, et al. The Lancet Commission on pollution and health. Lancet 2018; 391: 462-512.

11. Griswold MG, Fullman N, Hawley C, et al. Alcohol use and burden for 195 countries and territories, 1990-2016: a systematic analysis for the Global Burden of Disease Study 2016. Lancet 2018; 392: 1015-1035.

12. Zatoński $\mathrm{W}$ and the HEM Project team. Closing the health gap in European Union. Cancer Center and Institute, Warsaw 2008.

13. Zatoński WA, Sulkowska U, Zatoński MZ, et al. Alcohol taxation and premature mortality in Europe. Lancet 2015; 385: 1181.

14. Malnutrition. Key facts. Available from: http://www.who.int/ news-room/fact-s heets/detail/malnutrition (accessed: 19 October 2018).

15. Famine in Yemen could become one of worst in living memory, UN says. Available from: https://www.theguardian.com/ world/2018/oct/25/famine-in-yemen-could-become-one-ofworst-in-living-memory-un-says (accessed: 19 October 2018).

16. World food situation. FAO Food Price Index. Available from: http://www.fao.org/worldfoodsituation/foodpricesindex/en/ (accessed: 19 October 2018).

17. Chadwick E. Report on the sanitary conditions of the labouring population of Great Britain. W. Clowes and Sons, London 1843.

18. Snow J. On the mode of communication of Cholera. John Churchill, London 1849; 1-38.

19. http://www.censusindia.gov.in/ (accessed: 19 October 2018).
20. Immunization coverage. Key facts. Available from: http://www. who.int/en/news-room/fact-sheets/detail/immunization-coverage (accessed: 19 October 2018)

21. Cairns J. Cancer Science and Society. WH Freeman and Co., San Francisco 1978.

22. Seweryn M. Potential savings due to avoided hospitalizations and avoided production loses because of low influenza vaccination coverage in Poland. J Health Inequal 2018; 4(2): in print.

23. Measles cases hit record high in the European Region. Available from: http://www.euro.who.int/en/media-centre/sections/ press-releases/2018/measles-cases-hit-record-high-in-the-european-region (accessed: 19 October 2018).

24. Chatfield-Ball C, Boyle P, Autier P, et al. Lessons learned from the casualties of war: battlefield medicine and its implication for global trauma care. J R Soc Med 2015; 108: 93-100.

25. Webster D. Aftermath: The Remnants of War. Random House, New York 1996.

26. Bailey C. More Americans Killed by Guns Since 1968 Than in All U.S. Wars - Combined. Available from: https://www. nbcnews.com/storyline/las-vegas-shooting/more-americanskilled-guns-1968-all-u-s-wars-combined-n807156 (accessed: 19 October 2018).

27. Parascandola M. Recent youth e-cigarette trends in the US and Poland. J Health Inequal 2018; 4(2): in print. 


\section{Peter Boyle, Ph.D.}

Peter Boyle's appointment as President of the International Prevention Research Institute, Lyon, France follows immediately on his tenure as Director of the International Agency for Research on Cancer (IARC/WHO). From 1991-2004 he was Director of the Division of Epidemiology and Biostatistics at the Institute of Oncology in Milan, Italy. Prior to that he help posts as Senior Scientist at IARC, Assistant Professor in Epidemiology and Biostatistics at Harvard School of Public Health and the Dana-Farber Cancer Institute (Boston, United States), the West of Scotland Cancer Surveillance Unit (Glasgow, United Kingdom) and the Department of Medicine at Glasgow University.

Professor Boyle is the inaugural Director of the University of Strathclyde Institute of Global Public Health at iPRI, which is situated in Lyon and Glasgow. He is Professor of Global Public Health at the University of Strathclyde and is currently Visiting Professorship at Glasgow University. He is founder and President of the World Prevention Alliance, a non-governmental organisation committed to prevention research and actions in lower income countries.

Peter Boyle's research interests lie in disease prevention and translational research in its broadest sense, from translating cutting-edge scientific discovery into new approaches to treatment to translating information about risk factors into changes in population behaviour. He led the EUROCAN+PLUS project which developed priorities for coordination of cancer research in Europe and was Editor of the World Cancer Report 2008 and the State of Oncology 2013 which highlighted the growing global cancer crisis. The recent publication of State of Oncology in Africa 2015 and the accompanying film Cancer is... Killing Africa, highlight the need for action against chronic disease in low-resource countries. He has published 700 scientific articles in peer-reviewed journals and twenty books, $\mathrm{His} \mathrm{H}$-index has been calculated (Scopus) as 97.

Peter Boyle has previously been a Member of the European Cancer Advisory Board and worked as the scientific advisor to the European Commission on the European Tobacco Contents Directive which was voted into law in 2002. He was also responsible for revisions of the European Code Against Cancer.

Peter Boyle has been awarded the Knight's Cross of Order of Merit of the Republic of Poland (Krzyż Kawalerski Orderu Zasługi Rzeczypospolitej Polskiej); Fellowship of the Royal Society of Edinburgh; Honorary Membership in the European Society for Therapeutic Radiology and Oncology (ESTRO), the Hungarian Oncological Association and the Argentine Medical Association; Fellowship of the Royal College of Physicians and Surgeons (Glasgow); Fellowship of the Royal College of Physicians (Edinburgh); Honorary Fellowship of the Royal College of Physicians of Ireland; Fellowship of the Academy of Medical Sciences (United Kingdom); Membership of the European Cancer Academy; Membership of Academia Europea; and Honorary Membership of the Hungarian Academy of Science. He has been awarded honorary doctorates by the Universities of Aberdeen (DSC) and Dundee (LID). In July 2017 he was presented with the Royal Medal of the Royal Society of Edinburgh by Her Majesty Queen Elizabeth and in 2018 received the Chancellor's Medal of Strathclyde University.

\section{Presentation of Professor Boyle before his inaugural lecture}

Professor Peter Boyle has been a leading global cancer researcher since almost half a century. For decades, he was associated with the World Health Organization's International Agency for Research on Cancer, which he directed between 2004 and 2008. He worked at the most important institutions that take up the struggle against cancer. First in Glasgow, Scotland, where he was born. Then at Harvard University in the United States. Later in Milan, Italy, at the Institute of Oncology. Finally, over the recent decades, at the International Prevention Research Institute in Lyon, France. Currently, Professor Peter Boyle is conducting a crusade against cancer in Africa.

Peter, together with his wife, Helen, has raised and educated three daughters. All of them are doctors, specialists in cancer treatment.

Professor Peter Boyle is a great friend of Poland and my scientific partner of long standing. At the end of the $20^{\text {th }}$ century, we wrote together the 'Atlas of Cancer Mortality in Central Europe'. In 2004, we completed a monograph entitled 'Tobacco, Science, Policy and Public Health', which has become one of the seminal monographs on the fight against tobacco-related diseases in the world.

At the beginning of the $21^{\text {st }}$ century, together with Professor Boyle and Professor Wojtyła, we developed a strategy to fight against cancer in Poland - the so-called 'Warsaw Declaration'. We handed it over to the then Polish Minister of Health and Prime Minister. This study became the basis for the Polish National Cancer Prevention Programme 2006-2015. The President of the Republic of Poland decorated Professor Peter Boyle with the Knight's Cross of the Order of Merit of the Republic of Poland for his services to the health of the Polish nation.

Importantly, Peter is also a passionate supporter of Celtic Glasgow, and used to consider the Polish goalkeeper Artur Boruc, a godsend for Scotland. Peter was also crucial for my spiritual formation. When our work took us to various parts of the world together, Peter always made sure that we attended Holy Masses in Polish, which he adored. Thanks to him I know the schedule of services at Polish churches all over the world.

A few months ago, Professor Boyle signed a cooperation agreement with the Rector of the President Stanisław Wojciechowski State University of Applied Sciences in Kalisz. We are very excited that our European European Observatory of Health Inequalities in Kalisz will have the opportunity to conduct research with Professor Boyle and his team. It is a great honour for us that Professor Boyle will join us in strengthening the scientific programme of our university.

Witold A. Zatoński 